The International Journal of Multimedia \& Its Applications (IJMA) Vol.10, No.6, December 2018

\title{
DEVELOPMENT OF A CONCEPTUAL FRAMEWORK FOR MATHEMATICAL LEARNING SOFTWARE BASED on Exaggeration Principle, Motivational ELEMENTS AND CRITICAL AND CREATIVE THINKING SKILL
}

\author{
Nor Hasbiah Ubaidullah ${ }^{1}$, Aizu Khalili Zohedi ${ }^{1}$ And Norasikin Fabil ${ }^{2}$ \\ ${ }^{1}$ Faculty of Art, Computing \& Creative Industry, Universiti Pendidikan Sultan Idris, \\ Tanjung Malim, Malaysia \\ ${ }^{2}$ Faculty of Science and Technology, Universiti Sains Islam Malaysia, Nilai, Malaysia
}

\begin{abstract}
Several studies have shown that motivation elements can motivate students in learning mathematics. Thus, this study was carried out to examine the impacts of the application of animation exaggeration principle, critical and creative thinking skill (CCTS), motivation elements on the development of learning software. This study used a literature survey method to help highlight the appropriate elements of CCTS, exaggeration principle, and the Attention, Relevance, Confidence and Satisfaction (ARCS) model deemed necessary for the learning of integers of Form One Mathematic. Findings showed that the exaggeration principle, CCTS and motivation elements could be effectively applied to squash and stretch and character design of a kangaroo character through its movements on a line number. Through this study, a conceptual framework was developed based on the amalgam of elements of ARCS model, CCTS, and exaggeration principle, to which educational software developers and practitioners could refer to produce efficacious learning application for mathematics.
\end{abstract}

\section{KEYWORDS}

Animation exaggeration principle, ARCS model, critical and creative thinking skill (CCTS), learning of integers, Mathematics

\section{INTRODUCTION}

A study conducted by the Malaysia's Ministry of Education (MMOE) has revealed that Malaysia was one of the 74 countries that were at the bottom of the list for the learning performance of mathematics, science, and reading based on the 2009's Programme for International Student Assessment (PISA) [1]. In fact, Malaysia was poorly ranked among the countries surveyed for the learning of mathematic, precariously placed at 57 out of the 74 nations. According to the findings of The International Trends in Mathematics and Science Study (TIMSS), the percentage of students not meeting the stipulated benchmark is gradually increasing and, more alarmingly, students are failing to attain the minimum standard. Clearly, this alarming trend is made evident by the increase in the percentage of students not fulfilling the minimum standard, which saw the percentage climbed from 7\% in 1999 to $35 \%$ in 2011. Surely, such a worrying trend highlights the dire problem faced by this nation, which warrants more efforts to help raise the standard of learning of the subject matter. Definitely, mastery of learning in mathematics would be one of the important steps required to help elevate the position of Malaysia in the PISA ranking list. To 
The International Journal of Multimedia \& Its Applications (IJMA) Vol.10, No.6, December 2018

achieve this, the contents of mathematics have to be revamped that focus on higher-order thinking skills (HOTS), with which students have to master. According to Poh[2], HOTS for mathematics encompass skills in defining and interpreting problems, making estimations, arranging, making drawings, mental processing, assessing, classifying, making inferences, identifying polar, making generalizations, and differentiating. For this study, HOTS used were based on the higher-order thinking skills as defined by the Curriculum Development Centre of the MMOE's [3].

In mastering HOTS for the topic of integers of Form One Mathematics, students occasionally develop a few misconceptions in performing mathematical operations of integers. It is therefore imperative for them to develop the correct concepts such as to avoid making false understanding, conclusions, processes, and generalizations. For this to take place, students' thinking needs to be guided toward the proper direction of discovery and problem-solving process [4]. In this regard, differences in understanding between teachers and students can lead to ineffective teaching and learning process, as information delivered by the former and that perceived by the latter could contradict with one another, given the misunderstandings existing between the two parties. Unfortunately, such misunderstandings are quite prevalent among the majority of students in Malaysian schools. To date, several relevant agencies have identified a number of problems confronting students to master HOTS, especially in learning integers of the Form One Mathematics $[5,6]$. In general, students have been found to be weak and lacking in understanding of the concepts and mastery skills required to learn such a topic. Premised on this background, a preliminary analysis was conducted involving 120 Form One students who had already learned integers.

The main purpose of this analysis was to examine and analyse the level of achievements of students based on HOTS using a number of subjective questions. Predictably, a majority of students were found to be weak in most of the topics. Notably, they were observed to be extremely weak in the subtopic of problem solving of integers, namely addition and subtraction of integers. Apparently, such problems stemmed from students' poor technical skills in dealing with negative integers, which clearly warrants some measure of redress. According to Gullick [5], understanding negative numbers entails students to deal with values of less than zero ('0') (which obviously cannot be 'seen' physically) that renders a mathematical concept to be abstract. Naturally, teaching such a mathematical concept would overwhelm students as they have been exposed to learning only positive numbers for six years at the primary level. As such, it is hardly surprising to find students grappling with making comparisons among negative integers. This main problem seems to materialise as students have to assimilate and adapt negative numbers in their scheme of thinking when learning such integers, which sometime causes confusions and frustration among them [6]. Given the gravity of such a problem, it is imperative that teachers have to diversify their teaching strategies, such as using computer animations, to help their students master the appropriate concerts and skills in learning mathematics. Against this backdrop, the researchers undertook this study with the following objectives:

a. To determine the appropriate principles of animation exaggeration that can be applied for the learning of integers of Form One Mathematic.

b. To determine the appropriate HOTS that students need to master for the learning of integers of Form One Mathematic.

c. To determine the appropriate motivational elements that could help improve the learning of integers of Form One Mathematic.

d. To propose a conceptual framework for the development of a learning module for the learning of integers of Form One Mathematic based on the principles of animation exaggeration, HOTS, and motivational elements. 
The International Journal of Multimedia \& Its Applications (IJMA) Vol.10, No.6, December 2018

\section{Methodology}

The methodology of this study was based on a survey of related literature pertaining to the principles of animation exaggeration, HOTS, and ARCS' motivational elements for the learning of integers of Form One Mathematic. Elements determined from such a survey were used to develop the conceptual framework of the study.

\subsection{Animation}

Early animations, which are called celluloid animations, were developed based on hand drawings that were arranged in sequence. With the advent of computer technology, which began in 1970s, computer animators have created fluid, organic animations that could realistically mimic humans' movements. In this respect, the animation industry has been dominated by Walt Disney Studio. Through the glorious years producing such animations, its animators have gained vast experiences and insights, which helped them propose 12 animation principles for creating realistic animations [7]. The 12 principles are squash and stretch, anticipation, staging, straight ahead action and pose to pose animation follow through and overlapping action, slow in and slow out, arcs, secondary action, timing, exaggeration, weight, and appeal.

\subsubsection{Principle of EXaGgeration in ANIMATION}

In this study, the researchers capitalized on the advantages of the exaggeration principle to enhance the learning of integers. Essentially, exaggeration means that a character that is in a state of sadness would become sadder. Likewise, if such a character is in a state of happiness, it would become happier [7]. As such, appropriate use of exaggeration principle could help create realistic animations that would attract viewers' attention. Such principle could be applied to several elements, such as movements, facial expressions, squash and stretch, hops, or timings. In using one of these elements, application developers would be able to attract users and to ensure important information would not be overlooked.

Clearly, exaggeration principle could be used to emphasise a particular idea or action. Exaggeration is also viewed as an extreme movement with the main aim to attract the interest of an audience. For this to take place, exaggeration has to be applied to movements to ensure the audience would focus on the contents that are being presented. In this regard, the combination of principles of anticipation and staging could be used to heighten the audience's interest to the extent that they become consciously aware of the main issue being discussed. More importantly, the use of exaggeration principle must not be a distraction to the presentation, but it must be directed to helping the audience to focus on animations. For example, the animation of a jumping digital kangaroo could be created conventionally or developed using the exaggeration principle, and of which the latter would be more impactful than the former.

Exaggeration could be applied to such animations in either small or large quantity. It could be performed by speeding up the timing of action of an animation or making the character fully compressed prior to a jumping action. In addition, this principle relies on the level of realism required for an action. For instance, realistic actions only require minimum amount of exaggeration.

Moreover, to ensure students could become aware of and pay attention to the use of this principle, the rate of exaggeration for an animation has to be more than two time intervals. At this particular rate, students would have ample time to focus on the principle of animation exaggeration. According to Kwon and Lee's [8] paper titled Cartoon-like stylization for character animation, the exaggeration principle for animations could be applied using three methods based on several 
The International Journal of Multimedia \& Its Applications (IJMA) Vol.10, No.6, December 2018

modifications made to three of the 12 Walt Disney's animation principles, namely exaggeration based on sub-joint hierarchy, slow in and slow out filter, and squash and stretch stylization. In addition, the principle of exaggeration for animation could be applied to animations using Walt Disney's own animation principles through body language, squash and stretch, anticipation, and character design.

\subsubsection{APPLiCATION OF PRINCIPLE OF EXAgGERATION}

The application of principle of exaggeration is discussed in the following sections.

\subsubsection{Principle of Exaggeration through Body Language}

One of the methods in applying exaggeration principle in animation is by increasing the use of the body language of a character. In fact, body language could expressed the emotions of a character more meaningful than those expressed through dialogues [9]. Hence, the expression of a character needs to be expressed through the body language in addition to facial expression, and the application of exaggeration principle in animation could surely help achieve such expression [7]. For example, a character could be shown to have some difficulties in moving by using a proper body language, which could be achieved by adding more weight to the character's body than it normally has. As such, creating a character with the use of exaggeration through body language entails animators to create a normal character first. Thereafter, elements of exaggeration could be applied to the character, such as elongating its limbs or adding more weight to the character. Arguably, such character would be more appealing to the audience compared to the normal character. Such application of the body language is best exemplified through the film Aladdin, in which the character's emotions are expressed through the body language of the Magic Carpet, given that a carpet does not have a facial figure [10]. In this regard, exaggeration relies on the body language and movements of such character to create such happy and sad emotions. Thus, the exaggeration principle used in animation through body language and movements could convey compelling messages or ideas to the audience either physically or emotionally. Using this principle, the importance of any movement or a sequence of movements could be conveyed to the audience such that they could easily make sense of the actual contents and concepts that are being presented.

\subsubsection{Exaggeration Principle through Squash and Stretch}

Squash and stretch is a process that changes the form of an object to display the effect of a force on its movements. When the principle of animation exaggeration is applied to the force generated by a movement, a compelling, forceful effect would be created that helps captivate the audience. For example, in the animation movie, Rabid Rider [11], the main cartoon character, the Road Runner, was shown to have an elongated neck and detached limbs as it accelerated to run, giving the impression of extreme speed and strength of gravitational effect. In addition, the same principle was applied to squash and stretch for the animation of the Road Runner's nemesis, Wile $E$ Coyote, as it fell off from a tall cliff, the effect of which a thunderous sound of the body impact was produced, the aftermath of which the character looked completely flattened on the ground. Clearly, the above animation highlights the impact of force on objects. Figure 1 shows the exaggeration principle of squash and stretch.

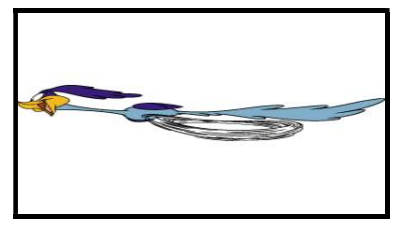

Figure 1. The exaggeration principle of squash and stretch 
The International Journal of Multimedia \& Its Applications (IJMA) Vol.10, No.6, December 2018

\subsubsection{Exaggeration principle through Anticipation}

Anticipation enables the audience to anticipate the type of movements made by the action of an object. In general, the anticipated movement would be in the direction that is opposite to the original movement. The application of exaggeration principle in anticipation enables an animation to be given greater and longer attention [12]. In addition, such principle in anticipation could be applied at the beginning of an animation to help the audience to predict the action that would be performed by an animated character.

\subsubsection{Exaggeration Principle in Character Design}

Applying the exaggeration principle in character design could help create characters with unique characteristics. For example, the design of an overweight character would look ordinary to many people, as it does not have any special characteristics that could attract their attention. However, the same character could evoke greater appeal and attract more attention by using such a principle such that it could be perceived to look more heavier than usual. Definitely, the exaggeration principle when applied appropriately could help emphasize such a physical appearance more vividly [13]. Figure 2 shows the exaggeration principle in the character design of an obese man.

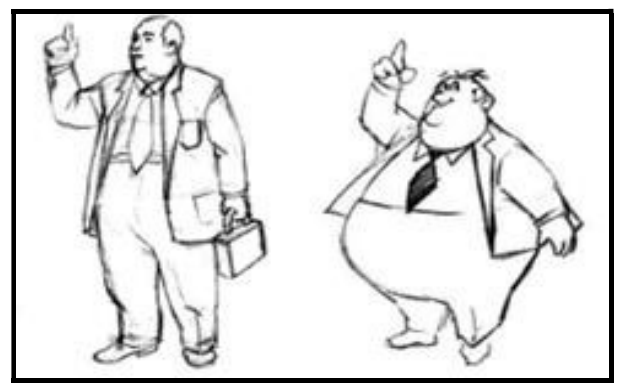

Figure 2. The exaggeration principle in the character design of an obese man

\subsubsection{Exaggeration Principle in the Study}

The exaggeration principle used in this study was based on the combination of squash and stretch and character design exaggeration. Such an approach was used in this study because of its relevancy to the specific needs of this study. In this study, the exaggeration principle was applied to the character design of an animated kangaroo such that its head would appear to look bigger than usual. In addition, the character's movements were manipulated by applying the same principle to squash and stretch using a line number to help emphasize the conceptual contents that needed to be conveyed to students. Based on the application of such principle, the kangaroo

character would move to the right to highlight the correct steps in the addition of integers. In contrast, the same character would move to the left to highlight the correct steps in the subtraction of integers. Figure 3 shows the application of exaggeration principle used in this study.

The exaggeration principle was first applied to the design of the kangaroo's head and then to its movements through squash and stretch, which could be seen as it started to jump, floated in midair, and landed on the ground. The application of squash and stretch helped generate the exaggeration effect on the movements of such animated character. Certainly, the application of such principle through character design and squash and stretch for the kangaroo's movements on

the line number of the educational software or learning application would help attract students' attention such that they would be able to understand the concepts of addition and subtraction of 
The International Journal of Multimedia \& Its Applications (IJMA) Vol.10, No.6, December 2018

integers more clearly, as they could watch the animated kangaroo moves in relevant directions on the line number for such mathematical operations. The imperative to acquire such conceptual understanding could not be overstated as it serves as the foundation for the successful learning of integers of the Form One Mathematic.

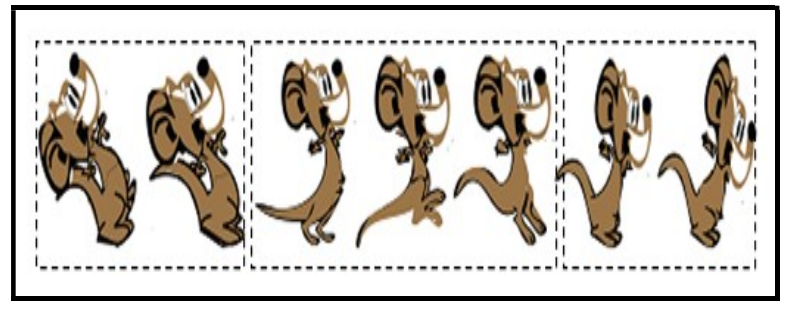

Figure 3. The application of exaggeration principle in the study

\subsubsection{THE IMPORTANCE OF EXAGgERATION PRINCIPLE}

Clearly, the effectiveness in using the exaggeration principle relies on the idea to be conveyed to the audience. In fact, having a sound understanding of a particular idea to be conveyed through exaggeration would help users to easily comprehend such an idea. As such, the exaggeration principle needs to be applied carefully and judiciously, the failure of which would inevitably create unrealistic animations. Definitely, not all actions, designs, objects and emotions would require such a principle as they could also be effectively presented through other means. Hence, a fine balance with regard to the use of exaggeration principle has to be made to ensure users would be able to understand the very idea that is being conveyed through realistic animations [14].

As emphasized earlier, exaggeration is a method that could help emphasize a particular idea or message, the emphasis that would highlight the importance of such an idea or that would help captivate the user. Therefore, with the proper use of exaggeration principle for relevant elements of learning, animators could guide users to identify and make sense of the idea or message being conveyed through effective, appealing animations. Arguably, without exaggeration, animations would be not only unrealistic but also unappealing. Moreover, normal movements tend to be unimpressive that might not be able to catch or sustain users' attention. As such, animators have to apply exaggeration principle to create appealing, realistic movements of objects such that users would devote their time and effort to learn the main idea being presented. Again, it needs to be emphasized that the application of such principle has be based on proper judgement, as excessive use of the principle could create illogical animations, which could be counterproductive.

\subsection{Critical ANd Creative Thinking Skill (CCTS)}

In general, critical and creative thinking skill (CCTS) has a number of definitions and components. According to Peg [15], CCTS refers to the ability of individuals to critically evaluate something before making a decision to either accept or to reject such a thing. More importantly, it is not merely about accepting a particular idea but more on understanding, analysing, and assessing a situation, and as well as anticipating the probable outcome of a decision in accepting or in rejecting such an idea. In other words, critical thinking skill is the skill required to examine information, situations, and facts in-depth [16]. Put simply, it involves collecting, analysing, testing, and evaluating information. In addition, such a skill helps individuals to differentiate facts from opinions.

In contrast, creative thinking skill is the skill that utilizes imagination and foresights in developing solutions, searching for alternatives, and seeing things in different perspectives [16]. Together, the conflation of this skill and the above skill leads to the formation of CCTS, which 
The International Journal of Multimedia \& Its Applications (IJMA) Vol.10, No.6, December 2018

also involves metacognition, with which students would need to enable them to think critically about a particular topic. In actuality, using metacognition would not only help them to apply what they have already learned but also help them to reflect on why they are thinking in a particular way, which surely represents a benchmark of educational success [17]. Accordingly, CCTS has to be applied rationally, meaning that an individual would have to think using relevant rational principles [18]. Therefore, the concepts of such an important skill have to be learned, trained, and practiced in individuals' daily routines and works.

\subsubsection{CCTS Model}

In recent years, the ACARA model of CCTS [19] has been used to help develop an integrated approach in the teaching curriculum of CCTS. According to this model, the organizational elements of CCTS could be divided into four important components, namely inquiry that involves exploration and identification of information, generation of ideas and possibilities, reflection on thinking, action and analytical process, and synthesis and assessment of information. These four components are interrelated that represent different aspects of thinking and have to be developed directly or indirectly among students. For this study, the main model of CCTS used was based on the MMOE's CCTS model [3]. Essentially, this model outlines the main elements of the critical and creative thinking skills that students have to master.

This model has been developed and structured based on a hierarchy of skills, ranging from simple to complex skills. Clearly, the mastery of such skills would depend on a particular title and topic of learning. In other words, different learning topics would entail students to utilize different sets of critical and creative thinking skills. Given that thinking skills are normally taught in sequence in the teaching and learning process, it is therefore important for students to learn and master the basic CCTS before they could learn the complex skills. On the one hand, creative thinking skill helps students to generate ideas, make inferences, formulate hypotheses, synthesize, and form mental pictures. On the other hand, critical thinking helps students to characterise, compare and differentiate, collect and classify, arrange and prioritize, analyse, identify inclination, and assess and make decisions. As such, if learning a particular topic requires students to make hypotheses, they have to master the skill needed to generate ideas, determine their relations, and make inferences. Clearly, students have to acquire and master the appropriate thinking skills deemed vital for a given title and topic of learning, as certain sets of thinking skills might not be required for a given topic. Hence, thinking skills that are required for a given learning topic must be determined first before students could start learning a given topic.

\subsubsection{Application of CCTS Model in the Study}

In this study, the CCTS that students must have for the learning of integers was arranged based on a given subtopic. Students must first identify the relevant knowledge about a skill, such as the skill in sequencing or arranging objects, facts or concepts, and then they must formulate questions related to a given situation that tested their mastery of CCTS in making sequences. Later, the students were given a new situation in which they were needed to apply the same skill as above. Hence, students could enhance such a skill by transferring it from existing context to a new context. The critical thinking skill that was required by students was the skill needed to help them to compare and differentiate, sequence and arrange, and analyse. With such a skill, students could read and write integers, compare values between two integers, and solve problems related to addition and subtraction of integers. Using the same skill, they could create a sequence of the learning outcomes to represent integers on a line number and to arrange integers in sequence. In addition, this skill helped them to analyse the learning outcomes such that they could accurately write positive and negative numbers to represent the correct mathematical expressions of integers. On the other hand, the creative thinking skill needed was to help them to form mental pictures of 
The International Journal of Multimedia \& Its Applications (IJMA) Vol.10, No.6, December 2018

concepts that they had learned with regard to the mathematical operations of addition and subtraction of integers.

\subsection{Model Motivation}

Unanimously, all scholars concur that motivation is one of the important aspects in the teaching and learning process. Many studies have shown that motivation has a huge impact on learning outcomes, because it serves as a vital factor to engage and encourage students to learn that leads to better learning performance. To date, several motivation theories and models of learning and instruction have been proposed, of which two models have been widely adopted in many studies, namely the ARCS model [20] and intrinsic motivation model [21]. The former model has four main components, namely attention, relevance, confidence, and satisfaction. Likewise, the latter model also has four main factors, namely challenge, curiosity, control, and fantasy. Interestingly, as stated by Bixler [22], these two popular motivation models share some similarities.

\subsubsection{ARCS Model}

The ARCS model was selected in this study because it has been consistently proven to be very effective in the design, development, and testing of instructional materials. This is not surprising given that this model has been designed to focus on instructional learning materials and to evaluate learning efficacy in the classroom [23]. To date, the ARCS model has been widely used in developing instructional materials, as it could neatly merge various aspects or elements of learning motivation theories, instructional design, and development process [24]. This model, which was developed by Keller [25], could be effectively used to improve students' motivation in learning, especially in using instructional materials. In fact, the development of this model was built upon on earlier theories, namely the Macro Motivation theory and the Instructional Design [26, 25, 20]. Principally, the ARCS model focuses on creating, simulating, and sustaining learning environments that stimulate students' motivation. In essence, this model is based on the Anticipated Outcomes theory, which postulates that students would be motivated to involve in a learning activity if they are satisfied with the values of such an activity and are confident to solve such activity. It is therefore imperative that learning activities have to be carefully planned and carried out to help motivate students and help them gain meaningful learning.

\subsubsection{Elements of ARCS Model}

According to Keller's ARCS model [25, 20], motivation in learning is influenced by four main components as follows:

a. Attention (A): to instil interest in students and to sustain their attention and curiosity with learning materials.

b. Relevance (R): to relate learning objectives, students' interests, motives, and use of future learning.

c. Confident (C): to develop students' confidence in learning and their capability in solving activities and assignments.

d. Satisfaction (S): to help students attain extrinsic and intrinsic learning satisfaction after solving assignments.

\section{FINDINGS AND DISCUSSION}

The findings of the study are discussed in Section 3.1 and Section 3.2. 
The International Journal of Multimedia \& Its Applications (IJMA) Vol.10, No.6, December 2018

\subsection{The Application of Animation Exaggeration Principle, CTSS, and ARCS MODEL IN THE STUDY}

In this study, the principle of animation exaggeration was applied in the development of animations, which were used to help students develop the required CCTS that they had to master in learning the topic of integers. In learning such a topic, students had to perform a number of mathematical operations that entailed such a skill, like comparing and differentiating integers. Interestingly, the study revealed that the animations were able to help students achieve the learning outcome in terms of reading and writing integers. In addition, they were observed to be able to successfully compare the values between two integers, which was the learning outcome based on the relevant CCTS, namely the ability to compare and to differentiate concepts or objects. Together, the attainment of these two learning outcomes suggests that learning using such animations could help students to acquire the appropriate CCTS, namely to compare and to differentiate. As demonstrated in this study, the mastery of CCTS was instrumental in helping the students to improve their learning achievement as they managed to answer all questions related to CCTS. Arguably, animations that are able to attract students' attention could help motivate them to explore in seeking information and develop new knowledge from existing ones [27, 28]. Moreover, in the process of learning and understanding the required concepts through such learning activities, students would be able to control their learning at their own rate and capability.

Relevance is the element of which students would identify the extent to which they find the learning materials to be important and why such materials are deemed vital. Such element could be tied to learning objectives and use of learning outcomes for future undertakings. Once students have understood the concepts to be learned and CCTS that needs to mastered through exaggeration, they would acknowledge the importance of the learning objectives that need to be attained. Naturally, the awareness of mastering the CCTS would have a positive impact on students' achievement, as they would willingly invest in more efforts to deal with given CCTS questions. In this respect, relevance could help students to relate their learning experiences with instructional learning materials being used. Hence, students would be able to understand the importance of learning and mastering the appropriate skills, with which they could apply in their future assignments or tasks. The strategy used in this study was based on the animations created from the reality and environment to which students were exposed. Probably, using such as strategy could help students to easily understand the element of relevance and the imperative to master the learning contents of the subject matter [29].

Confidence is the third element of the ARCS model. Exaggeration could help emphasize the concepts that students need to focus on and to identify the CCTS that needs to be mastered, ultimately helping them to make sense of the relevance of learning specific concepts or facts. With better understanding of relevance, students would be able to develop stronger confidence, with which they could answer all questions given to them. As such, confidence needs to be instilled in students at the outset of the learning process, as it could heighten students' efforts to solve problems and achieve learning objectives. Therefore, learning has to be made meaningful such as to help students build strong confidence in learning. Moreover, this kind of positive attitude would help improve students' achievement as they would be able to answer CCTS-related questions confidently. Obviously, the important strategy in developing strong confidence among students lies with the ability of students to control the learning activities in which they are engaged. As such, the frequency of giving feedback to students' answers and clues for such questions would have a huge impact on the development of their confidence in problem solving.

Satisfaction helps provide positive reinforcement for students in their efforts in solving a given assignment. In this regard, exaggeration could help attract students' attention, generate a sense of 
The International Journal of Multimedia \& Its Applications (IJMA) Vol.10, No.6, December 2018

relevance in learning, and develop their confidence to master the required CCTS. Using such a set of skills, students would be able to achieve the intended learning objectives, which naturally provide them the satisfaction in pursuing academic endeavours. In addition, students would be provided with extrinsic rewards that help motivate them. Without doubts, satisfaction could materialise when students are able to utilize newly acquired skills or knowledge in solving tasks and in receiving appropriate, prompt feedback to help them generate positive attitude toward such tasks. Furthermore, this construct (satisfaction) could provide students with the necessary reinforcement to sustain the desired learning consistency [20]. In particular, the strategy involving the use of encouraging words, rewards for correct answers, and words of compliments, could surely enhance their satisfaction in learning. It is therefore importance to ensure students would remain satisfied and happy throughout the learning process [30]. It also needs to be emphasized that students' ability to generate new knowledge at the end of each learning session would be the primary motivation in providing them with the satisfaction that they really need. As such, all the motivation elements of ARCS have to be sustained all the time in the learning process, the failure of which would result in dire consequences, such as students losing their motivation to learn and failing to achieve the learning objectives. Put simply, students with high motivation would naturally strive hard and give full commitment in their learning, which would have a profound positive impact on their learning achievement.

\subsection{CONCEPTUAL FramewORK OF THE STUDY}

The conceptual framework of the study was developed based on a detailed study of students' interest in learning integers. Specifically, two methods in learning integers as prescribed in the main textbook of the Form One Mathematic were tested, namely the method of line number and the method of particles collection. As observed, students exhibited greater interest in learning using the former method compared to their interest in learning using the latter method. In light of this particular finding, appropriate animations were developed for learning using the line number method. Given that students showed greater keenness in such a method, they were likely to be more motivated in learning, which helped them learn and gain a better understanding of the intended concepts and learning contents more readily. Moreover, the exaggeration principle was effectively applied in the animations of learning materials based on this learning method.

Admittedly, 12 Walt Disney's [15] basic principles of animation could be used for the animation of learning method based on integer line number. For this study, only one basic principle, namely exaggeration, was used. This principle was applied to the character design and movements of object for the learning method based on line number. In fact, the application of such animation principle was in line with the use of ARCS motivation model in the development of the required learning module, as it was deemed appropriate for the study of students' attitudes and motivation. In this study, all the elements of ARCS model, such as attention, relevance, confidence, and satisfaction, were successfully embedded in the learning module. Particularly, the development of such learning module was carried out by focussing on relevant, important aspects related to CCTS, line number learning method, and principle of animation exaggeration. Essentially, the module consists of several subtopics of integers deemed vital for the learning of Form One Mathematic, namely the introduction to numbers, addition of integers, and subtraction of integers. For such subtopics, the learning contents contain CCTS-related elements, and the principle of exaggeration was applied to the animation of a kangaroo character on the line number. As emphasized earlier, the CCTS employed in this study was derived from the elements of MMOE's model of critical and creative thinking skills [3] and ACARA [19], with which students were required to master in learning the topic of integers of the Form One Mathematic. Equipped with the necessary critical skill, they were able to compare and differentiate, analyse, and form sequence of integers, while the relevant creative skills helped them form correct mental pictures of the concepts of integers. 
The International Journal of Multimedia \& Its Applications (IJMA) Vol.10, No.6, December 2018

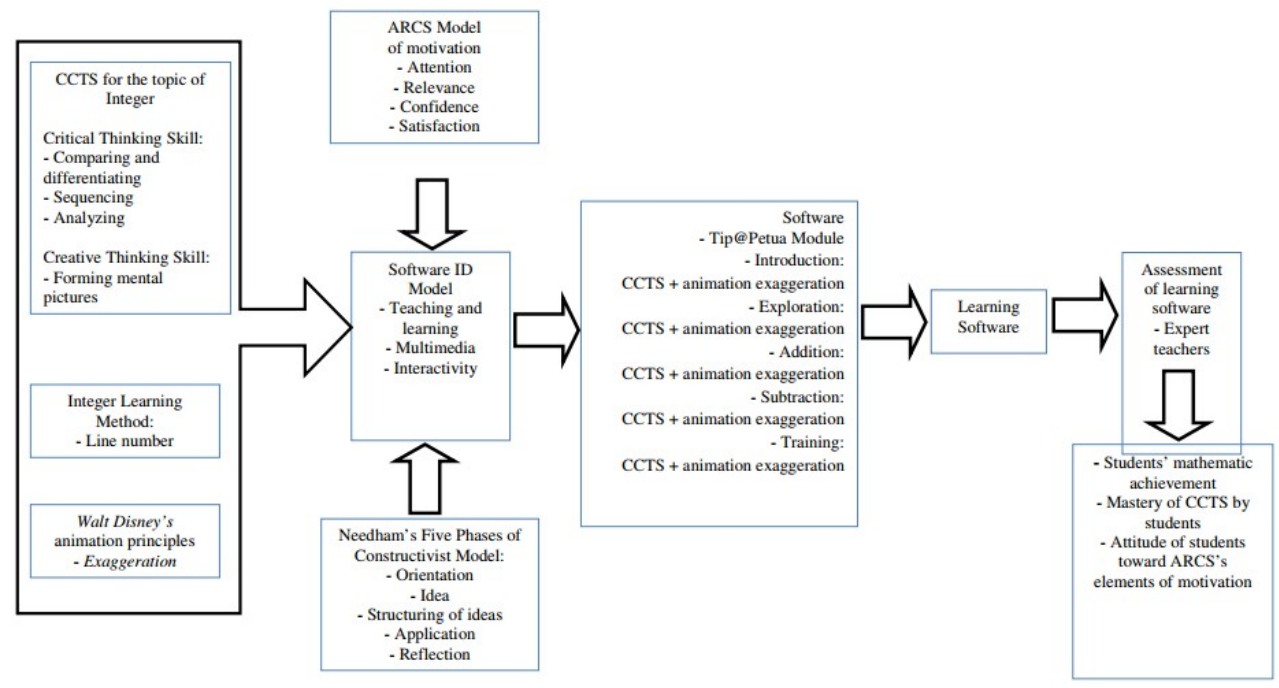

Figure 4. Conceptual framework of the study

\section{Conclusion}

This paper provides a detailed account of the application of the principle of animation exaggeration, CCTS, and elements of ARCS model in the learning of the topic of integers of the Form One Mathematic using a computer-based learning module. Specifically, the principle of animation exaggeration was applied to squash and stretch and character design of a kangaroo that would move along a line number. The critical thinking skill needed by students would enable them compare and differentiate, analyse, and form sequence of integers. Meanwhile, the creative thinking skill required would assist them to form appropriate mental pictures of the concepts of integers. Interestingly, the use of such an innovative, novel learning module was found to be effective as students were able to correctly read and write integers, compare values between two integers, and solve problems related to addition and subtraction of integers. Equally compelling was that the four elements of ARCS model, namely attention, relevance, confidence, and satisfaction, were successfully realised, indicating that students gained strong motivation to learn the subject matter with interest. In summation, the promising findings of this study provide compelling evidence that the amalgam of elements of the ARCS model of motivation, CCTS, and principle of animation exaggeration could help guide the development of an effective learning framework, with which software developers could use to develop efficacious computer-based learning applications to help students in learning mathematical concepts, such as the concepts of integers.

\section{ACKNOWLEDGEMENTS}

The authors would like to thank everyone who had provided his or her insights and expertise that helped contributes to the successful completion of the research. The guidance and support rendered are very much appreciated.

\section{REFERENCES}

[1] Kementerian Pendidikan Malaysia, (2013). Pelan pembangunan pendidikan Malaysia (2013-2025). Kuala Lumpur: Kementerian Pendidikan Malaysia.

[2] Poh, S. H. (2000). KBKK : Kemahiran berfikir secara kritis dan kreatif. Subang Jaya, Selangor: Kumpulan Budiman Sdn. Bhd. 
The International Journal of Multimedia \& Its Applications (IJMA) Vol.10, No.6, December 2018

[3] Pusat Perkembangan Kurikulum (2002). Kemahiran berfikir dalam pengajaran dan pembelajaran. Kuala Lumpur: Kementerian Pendidikan Malaysia.

[4] Brumbaugh, K., \& Rock, D. (2006). Teaching secondary mathematics. [3rd ed.]. Lawrence Erlbaum Assosiates: New Jersey.

[5] Gullick, M. M. (2012). Understanding less than nothing: investigations into the representation of negative numbers. Doctoral dissertation, Dartmouth College. Hanover, New Hampshire.

[6] Vlassis, J. (2004). Making sense of the minus sign or becoming flexible in 'negativity'. Learning and Instruction, 14, 469-484.

[7] Thomas F., \& Johnston O. (1995). The Illusion of Life: Disney Animation. Hyperion. Walt Disney Production:USA.

[8] Kwon, J. \& Lee, I. K. (2011), Cartoon-like stylization for character animation, Ubiquitous Virtual Reality International Symposium .

[9] Hook, Ed. (2003), Acting for animators - A complete guide to performance animation. Revised Ed. Heinemann.

[10] Aladdin (1992). [Film]. Directed by Clement, R., \& Musker, J. USA: Disney.

[11] Rabid Rider (2010). [Film] Directed by Matthew O., Warner Bros.

[12] Maestri, G. (2006). Digital character animation 3. Illustrated revised Ed. New Riders.

[13] Hedgpet, K. \& Missal, S. (2003). Exploring drawing for animation: the art and technique for drawing for 2D animation. Illustrated Ed. Cengage Learning.

[14] Lasseter, J. (1987). Principles of traditional animation applied to 3D computer animation. ACM Computer Graphics, 21(4), 35-44.

[15] Peg Tittle. (2011). Critical thinking: an appeal to reason. New York.Routledge:1-10 Ponce, G. A. (2007). It's all in the cards. Mathematics teaching in the Middle School 13(1), 10-17.

[16] Paul, R., \& Elder, L. (2006). Critical thinking: the nature of critical and creative thought. Journal of Developmental Education, 30(2), 34-35.

[17] Szabo, Z., \& Schwartz, J. (2011). Learning methods for teacher education: the use of online discussions to improve critical thinking. Technology, Pedagogy, and Education. 20(1), 79-94.

[18] Nickerson,R. S. (2008). Aspects of rationality: Reflections on what it means to be rational and whether we are. New York, NY: Psychology Press.

[19] Australian Curriculum Assessment and Reporting Authority (ACARA), (2012). Critical and CreativeThinking. Retrieved on 29 August 2011. http:/www.australiancurriculum.edu.au/GeneralCapabilities/critical-and-creativethinking/introduction/background.

[20] Keller, J. M. (1987). Development and use of the ARCS model of motivational design. Journal of Instructional Development, 10(3), 2-10.

[21] Malone, T. W., \& Lepper, M. R. (1988). Making learning fun: A taxonomy of intrinsic motivations for learning. In R. E. Snow \& M. J. Farr (Eds.). Aptitude, learning, and Instructions 3. Cognitive and affective process analyses. (pp. 229 - 253). Hillsdale,NJ: Erlbaum.

[22] Bixler, B. (2006). Motivation and its relationship to the design of educational games. Paper presented at the NMC. Cleveland, Ohio. Retrieved from http://archive.nmc.org/events/2006summerconf/materials/Bixler/m\&g.pdf.

[23] Kim, J. (2005). Physicalism, or Something Near Enough. New Jersey, NJ: Princeton University Press.

[24] Huang, D. W. H., \& Johnson, T. (2002). Motivational level of a computer-based simulation: A formative evaluation of the US Army Recruiting Simulation (USAREC). 2002 Annual ProceedingsDallas, 179.

[25] Keller J. M. (1983). Motivational design of instructional-design theories and models. Hillsdale, NJ: Erlbaum.

[26] Yin Xiaoteng (2015). A study of the effect of multimedia courseware on oral college English teaching. Journal of Language Teaching and Research, 6(5), 1106-1114. DOI: http://dx.doi.org/10.17507/jltr.0605.25.

[27]Tong Pang (2015). Research on the applications of multimedia technique in the mathematical teaching and education, International Conference on Economy, Management and Education Technology.

[28] Zeena, A. S., \& Karim, Q. H. (2016). 3D Simulation system for physical lab using an object oriented approach. International Journal of Computer Applications, 143(1).

[29] Kolokouri, E., \& Plakitsi, K. (2016). A CHAT approach of light and colors in Science teaching for the early grades. World Journal of Education, 6(4). 
The International Journal of Multimedia \& Its Applications (IJMA) Vol.10, No.6, December 2018

[30] Mantzicopoulos, P., \& Patrick, H. (2011). Reading picture books and learning Science: Engaging young children with informational text. Theory Into Practice 50(4), 269-276.

\section{Authors}

Dr. Nor Hasbiah Ubaidullah is as a Senior Lecturer in Faculty of Art, Computing and Creative Industry, Sultan Idris Education University. She had obtained her first degree (BSc. with Hons. Computer Science) from Malaysia National University, Malaysia and her master's degree (MSc. Information Systems) from University of Salford UK. She has a $\mathrm{PhD}$ in Information Technology from Malaysia National University. She has been teaching in higher education institutions since 1991 in several subjects such as Programming, Courseware Engineering and Information Systems Development. She has more than 25 years of teaching experience.

Dr. Aizu Khalili Zohedi has degree in Computer Science from Universiti Sains Malaysi, master in IT Education from Universiti Pendidikan Sultan Idris. He obtained his $\mathrm{PhD}$ degree in Multimedia Education from Universiti Pendidikan Sultan Idris. His research interest includes Multimedia and Programming $\mathrm{C}++$.

Dr. Norasikin Fabil is working as a Senior Lecturer at Universiti Sains Islam Malaysia. She received degree in Information Technology from Universiti Utara Malaysia and master of Information Technology from Universiti Kebangsaan Malaysia. She obtained her $\mathrm{PhD}$ degree in Information Science from Universiti Kebangsaan Malaysia. Her research areas include Information Visualization, Multimedia, ID and HCI.
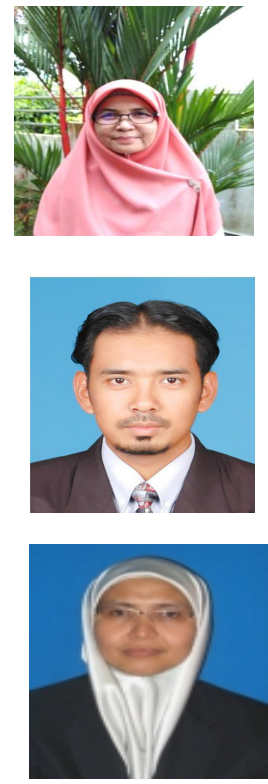